\section{DANÇA EDUCATIVA PARA CRIANÇAS COM DEFICIÊNCIA FÍSICA: REPERCUSSÕES DE UM PROGRAMA DE ENSINO}

\author{
EDUCATIONAL DANCE FOR CHILDREN WITH PHYSICAL DISABILITIES: \\ REPERCUSSIONS OFA TEACHING PROGRAM C?
}

DANZA EDUCATIVA PARA NIÑOS CON DISCAPACIDAD FÍSICA: REPERCUSIONES DE UN PROGRAMA DIDÁCTICO C己

doi' https://doi.org/10.22456/1982-8918.102748

(iD) Patricia Rossi-Andrion* <patriciarossi.pr@hotmail.com>

(iD) Mey de Abreu van Munster*<mey.munster@gmail.com>

*Universidade Federal de São Carlos. São Carlos, SP, Brasil.
Resumo: Este estudo teve como objetivos: analisar o envolvimento dos participantes com deficiência física em determinados elementos (rolamentos e deslocamentos pelo espaço envolvendo os níveis, as direções e os fatores de movimento) de um programa de dança educativa; e verificar em quais aspectos analisados pela escala de avaliação em dança educativa a intervenção promoveu maior ou menor influência. Trata-se de uma pesquisa de campo do tipo estudo de avaliação de programa. Participaram quatro crianças com deficiência física. Os instrumentos de coleta de dados foram: diário de campo e Instrumento de Acompanhamento da Aprendizagem em Dança Educativa. A análise dos dados foi realizada de forma quali-quantitativa (estatística descritiva). Observou-se que as habilidades e os elementos que indicaram ganhos expressivos foram: lateralidade, ritmo de movimentos, exploração de direções (frente, lado e trás) e dos níveis de espaço (baixo, médio e alto), compreensão e realização dos fatores de movimento "fluência", "peso", "tempo" e "espaço".

Palavras chave: Dança. Criança. Pessoas com deficiência. Educação Especial.
Recebido em: 07 mai. 2020 Aprovado em: 03 mar. 2021 Publicado em: 03 abr. 2021

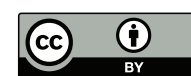

Este é um artigo publicado sob a licença Creative Commons Atribuição 4.0 Internacional (CC BY 4.0).

elSSN: 1982-8918 


\section{INTRODUÇÃO}

No Brasil, estudos envolvendo a dança e pessoas com deficiência vêm se desenvolvendo desde a década de 1980 e demonstram um crescente aumento devido aos benefícios que esta prática pode proporcionar a essa população. Tais benefícios abrangem aspectos motores, sociais, cognitivos e emocionais, como, por exemplo, melhorias acerca da reabilitação, do desenvolvimento do gesto motor, da postura, da coordenação, do ritmo, da movimentação articular, da autoconfiança, da comunicação e da relação interpessoal (ROSSI; MUNSTER, 2013; MAUERBERG-DECASTRO, 2005), bem como oportunizar uma transformação pessoal e social de forma que qualifique e preze pela diversidade (SANTOS; GUTIERREZ; ROBLE, 2019).

Ferreira (2000) e Ferreira e Ferreira (2004) pontuam benefícios que a dança pode proporcionar às pessoas com deficiência física, como a contribuição positiva em promover diferentes possibilidades de movimentos, desenvolver o autoconhecimento e a comunicação, melhorando as habilidades motoras específicas que auxiliam no cotidiano.

Muitos são os estudos que envolvem a prática da dança junto às pessoas com deficiência, sobretudo aquelas com impedimentos físico-motores: Bernabé (2001) elaborou e propôs um programa de dança para pessoas usuárias de cadeiras de rodas, visando ao processo do ensino da dança. Machado (2010) desenvolveu a dançaterapia e demonstrou melhorias acerca da qualidade de vida, pois além da dança auxiliar na postura e na funcionalidade da pessoa com deficiência física, ainda influencia positivamente em aspectos sociais e emocionais. Lopes (2011) avaliou o autoconceito e a identidade social de bailarinos cadeirantes profissionais que praticam a Dança em Cadeira de Rodas. Paula (2010) avaliou aspectos acerca do rendimento de bailarinos da Dança Esportiva em Cadeira de Rodas, verificando a frequência cardíaca e o lactato, afirmando esta ser uma atividade de alto rendimento.

Tais estudos, em sua maioria voltados à fase adulta do desenvolvimento de pessoas com deficiência física, envolvem propostas em diferentes contextos (educacional, de reabilitação, artístico e esportivo) nos quais a dança pode estar inserida, com finalidades diversas (pedagógica, terapêutica, performática e competitiva).

A respeito da dança e o público infantil, verifica-se que são poucos os estudos existentes na literatura científica voltados a crianças com deficiência ${ }^{1}$. Podem ser citados alguns, como o estudo de Santos e Braga (2010), em que a dança beneficiou o comportamento, a autoestima e a saúde mental; e o estudo de Silva, Carvalho e Millen Neto (2009), os quais verificaram que a dança em cadeira de rodas promoveu melhorias nos aspectos motores, na autonomia e na autoestima. Ambos envolveram crianças com paralisia cerebral, tendo a finalidade terapêutica como escopo. Todavia, não foram encontrados estudos nacionais que envolvessem crianças com deficiência física, independentemente de sua etiologia, tendo a finalidade pedagógica como propósito.

\footnotetext{
1 Mesmo utilizando o termo "Danceability" como expressão de busca, não foi possível encontrar artigos científicos referentes a tal manifestação voltada a crianças com deficiências. Foram encontrados apenas relatos de experiência e reportagens em jornais e revistas, os quais abordam a temática de forma superficial.
} 
Embora haja possíveis maneiras de se desenvolver a dança para pessoas com deficiência física, o presente estudo centrou-se sobre o processo de ensino e aprendizagem de habilidade ${ }^{2}$ e elemento ${ }^{3}$ da dança, sendo evidenciada a finalidade pedagógica, voltada a contextos predominantemente educacionais.

Tendo em vista o processo de ensino e aprendizagem de habilidades e elementos da dança junto a crianças com deficiência física, foi enfatizada a "dança educativa". Laban (1990) descreve que a dança deve ter uma proposta educativa, proporcionando movimentos naturais de expressão, espontâneos e criativos e que promovam o desenvolvimento e a capacidade de dançar e relacionar-se com o mundo. Segundo o autor, o movimento é um elemento básico da vida e deve ser orientado e estruturado com a finalidade de proporcionar o desenvolvimento de cada um, justificando a educação por meio da dança. Considerando o referencial teórico com fundamentação em Laban (1990), no presente estudo foi empregado o termo "dança educativa" ao se referir à dança como um meio para educar, instruindo os que a praticam.

Evidenciando o desenvolvimento individual, ressalta-se a importância de a dança educativa ser desenvolvida junto a crianças com deficiência física, por estas apresentarem padrões de movimento diferenciados daqueles observados em crianças sem limitações motoras, considerando a interferência de possíveis restrições na amplitude de movimento e/ou alterações de tônus muscular, que podem influenciar/ alterar sua funcionalidade (GUERZONI et al., 2008).

Ao desenvolver um programa de "dança educativa" a essa população, além de educar por meio dança e proporcionar o desenvolvimento de cada um, é importante atentar-se para o processo de ensino e aprendizagem do indivíduo, e não para o produto (LABAN, 1990). Sendo assim, deve-se envolver uma avaliação somativa de tudo o que foi desenvolvido durante o programa, nesse caso, a dança educativa. Esse processo deve ser avaliado pelo professor por meio da observação, para que sejam pontuadas as limitações e as habilidades dos alunos, buscando a análise e a adequação do ensino para que, então, seja verificado se o aluno compreendeu determinado conhecimento (SOUZA, 1994).

Concomitantemente, a estrutura do programa também deve ser organizada e adequada à população em questão. Segundo Freire (2001), um programa de dança para pessoas com deficiência pode ser eficiente quando: desenvolve a consciência integral de um indivíduo; centraliza corpo, mente e emoção; amplia os repertórios de movimento; facilita o autoconhecimento do corpo por meio da interação social; observa e analisa o movimento humano; considera a singularidade de cada corpo; reproduz e divulga o conhecimento a partir da experiência.

A partir desses referenciais, este estudo teve como objetivos:

- Analisar o envolvimento dos participantes com deficiência física em determinados elementos (rolamentos e deslocamentos pelo espaço envolvendo os níveis, as direções e os fatores de movimento) de um programa de dança educativa;

\footnotetext{
2 Entendemos como habilidades aquelas que podem ser desenvolvidas por meio da dança como a lateralidade e o equilíbrio.

3 Entendemos como exemplo de elementos da dança os rolamentos e deslocamentos pelo espaço envolvendo os
} níveis, as direções, os fatores de movimento (LABAN, 1990). 
- Verificar em quais aspectos analisados pela escala de avaliação em dança educativa a intervenção promoveu maior ou menor influência.

\section{MÉTODO}

O presente estudo, com enfoque misto (SAMPIERI; COLLADO; LUCIO, 2006), caracterizou-se como uma pesquisa de campo do tipo estudo de avaliação de programa (MARCONI, LAKATOS, 2008).

Dessa forma, este estudo avaliou os efeitos e resultados de um programa de dança educativa por meio do Instrumento de Avaliação em Dança Educativa (IAADE), ambos (tanto o programa quanto o instrumento) desenvolvidos pela pesquisadora.

O projeto em questão foi submetido ao Comitê de Ética e Pesquisa em Seres Humanos da Universidade Federal de São Carlos - CEP/UFSCar e aprovado pelo parecer n. 72041.

\subsection{PARTICIPANTES DA PESQUISA}

A amostra foi constituída por quatro participantes com deficiência física com idade entre nove e 14 anos, que obtiveram frequência superior a $75 \%$ em um programa de dança educativa. O Quadro 1 apresenta as características dos participantes.

Quadro 1 - Características dos participantes da pesquisa.

\begin{tabular}{|c|c|c|c|c|c|c|}
\hline Participante & Idade & Gênero & Etiologia & Classificação & $\begin{array}{c}\text { Dispositivos } \\
\text { auxiliares }\end{array}$ & $\begin{array}{c}\text { Experiência } \\
\text { motoras }\end{array}$ \\
\hline P1 & 14 & F & $\begin{array}{c}\text { Paralisia } \\
\text { cerebral }\end{array}$ & $\begin{array}{c}\text { Diparesia } \\
\text { espástica }\end{array}$ & - & Fisioterapia \\
\hline P2 & 10 & M & $\begin{array}{c}\text { Paralisia } \\
\text { cerebral }\end{array}$ & $\begin{array}{c}\text { Hemiparesia } \\
\text { esquerda }\end{array}$ & - & $\begin{array}{c}\text { Fisioterapia/ } \\
\text { Natação }\end{array}$ \\
\hline P3 & 9 & M & Artrogripose & - & - & Fisioterapia \\
\hline P4 & 11 & M & $\begin{array}{c}\text { Paralisia } \\
\text { cerebral }\end{array}$ & $\begin{array}{c}\text { Diparesia } \\
\text { espástica }\end{array}$ & Órtese & Fisioterapia \\
\hline
\end{tabular}

Fonte: elaboração própria.

\subsection{O PROGRAMA DE DANÇA EDUCATIVA}

O programa de dança educativa foi baseado em uma intervenção com duração de 12 semanas, com frequência de dois encontros semanais de 50 minutos cada, totalizando 24 sessões. Cada sessão foi constituída por quatro momentos distintos:

a. Contato com o próprio corpo (CC): voltado à exploração e autodescoberta do corpo de cada participante;

b. Contato com o outro (CO): partindo da percepção e reconhecimento de suas próprias capacidades e limitações, o participante inicia a interação por meio do "contato com o corpo do outro";

c. O corpo no espaço (CE): o participante é incentivado a compreender a interação de seu "corpo em deslocamento pelo espaço"; 
d. O corpo em movimento (CM): visando à integração e generalização das informações adquiridas corporalmente, as "possibilidades corporais de movimento" envolvem todo o conteúdo aprendido desde o início da intervenção.

Os conteúdos dos momentos citados acima se basearam no fluxo do movimento, nas possibilidades do espaço, nas qualidades dos movimentos, nas formas e nas trajetórias descritas pelo estudioso Laban (1990), envolvendo a exploração das direções (frente, lado, trás); dos níveis de espaço (baixo, médio e alto) e dos fatores de movimento (fluência - livre e contida, espaço - direto e flexível, peso - leve e firme, tempo - sustentado e súbito).

\subsection{INSTRUMENTOS DE COLETA DE DADOS}

Os instrumentos utilizados para coleta de dados foram: 1) o diário de campo, que compreendeu registros feitos pela pesquisadora durante o processo de intervenção e de coleta de dados; 2) Instrumento de Acompanhamento da Aprendizagem em Dança Educativa ${ }^{4}$ (IAADE) aplicado ao final de cada sessão.

Esse instrumento foi elaborado pela pesquisadora tendo como base sua experiência pessoal em dança associada aos fundamentos descritos por Laban (1990) como apoio teórico. Ele consistiu em 21 questões que acompanharam a aprendizagem desenvolvida e observada durante um programa de dança educativa. Dessas 21 questões, nove avaliaram o momento "Contato com o próprio corpo (CC)"; duas avaliaram o "Contato com o outro (CO)"; oito "O corpo no espaço (CE)"; e duas "O corpo em movimento (CM)".

Cada uma dessas questões tem pontuação de um a cinco, sendo descrita como Insuficiente (a), Regular (b), Bom (c), Muito Bom (d) e Ótimo (e), podendo alcançar a pontuação máxima de 105 pontos. Ressalta-se que este instrumento se encontra em situação de validação por juízes.

\subsection{PROCEDIMENTO DE COLETA DE DADOS}

O IAADE avaliou a aprendizagem de cada participante sessão a sessão, envolvendo habilidades e elementos da dança desenvolvidos durante todo o programa, sendo uma avaliação somativa. Ao final de cada sessão, o instrumento foi preenchido e, mediante essa avaliação, foi possível verificar o nível de aprendizagem dos participantes referente às atividades desenvolvidas. Com a avaliação realizada, foi desenvolvido o planejamento e foram elaboradas as atividades no decorrer do programa com diferentes graus de dificuldades com a finalidade de possibilitar a assimilação da aprendizagem e promover o ensino de novos conteúdos.

O IAADE está relacionado com o cronograma da programação em dança educativa, dividido em quatro momentos (descritos no item 2.2): 1) contato com o próprio corpo; 2) contato com o outro; 3) o corpo no espaço; e 4) o corpo em movimento. Essa subdivisão em habilidades e elementos da dança foi organizada com a finalidade de facilitar a avaliação sessão a sessão e verificar até qual momento

4 Acesso ao Instrumento de Acompanhamento da Aprendizagem em Dança Educativa (IAADE) na íntegra disponível em https://repositorio.ufscar.br/handle/ufscar/3160. 
do programa os participantes conseguiriam avançar. O Quadro 2 descreve os conteúdos com suas respectivas habilidades e elementos:

Quadro 2 - Descrição dos conteúdos desenvolvidos nos momentos que foram seguidos pelo programa de dança educativa.

\begin{tabular}{|c|c|}
\hline Momento do programa & Conteúdos \\
\hline $\begin{array}{c}\text { "contato com o próprio } \\
\text { corpo" }\end{array}$ & $\begin{array}{c}\text { controle corporal ao sentar-se e ao levantar-se, o controle postural na } \\
\text { posição sentada e em pé, a mobilidade articular, o esquema corporal, a } \\
\text { lateralidade, o ritmo e o equilíbrio. }\end{array}$ \\
\hline "contato com o outro" & $\begin{array}{c}\text { a interação entre os participantes e o contato físico e visual com os } \\
\text { colegas e com o professor. }\end{array}$ \\
\hline "o corpo no espaço" & $\begin{array}{l}\text { deslocamento em pé e no chão pelo espaço; orientações espaciais } \\
\text { (direções durante o deslocamento e níveis de espaço) e compreensão } \\
\text { dos termos tempo, espaço, peso e fluência descritos por Laban. }\end{array}$ \\
\hline $\begin{array}{l}\text { "o corpo em } \\
\text { movimento" }\end{array}$ & $\begin{array}{l}\text { fatores de movimento em conjunto (tempo, espaço, peso e fluência), a } \\
\text { criação de movimentos e a improvisação. }\end{array}$ \\
\hline
\end{tabular}

Fonte: ROSSI (2014, p. 63).

As sessões tiveram como característica uma aula de dança educativa, tendo como estrutura: parte inicial, parte principal e parte final. A parte inicial, com duração de cinco a dez minutos, envolveu a recepção e acolhida dos participantes, visando identificar as curiosidades e expectativas individuais e do grupo por meio de relatos pessoais. Ainda na parte inicial foram desenvolvidas dinâmicas e atividades do tipo "quebra-gelo", de forma a favorecer o entrosamento do grupo, aquecimento das articulações do corpo e alongamentos acompanhados de música, buscando envolver os participantes com movimentos fluidos e coreográficos. A parte principal, com duração de 30 a 40 minutos, enfatizou o "momento" do programa e seus conteúdos (Quadro 2) acompanhados de músicas ou sons corporais. A parte final, com duração de 5 a 10 minutos, envolveu exercícios voltados ao alongamento, relaxamento, massagens e/ou uma roda de conversa com a finalidade de abordar os conteúdos desenvolvidos bem como as percepções dos alunos referentes à sessão como um todo. Dessa maneira, todas as sessões tiveram tal estrutura e objetivos a serem seguidos.

Inicialmente, a parte principal da sessão envolveu atividades como: equilíbrio, esquema corporal, autonomia ao sentar-se e levantar-se, para que então, gradativamente, fossem inseridas a interação visual e corporal com o outro, deslocamento pelo espaço, compreensão dos fatores de movimento (tempo, espaço, peso e fluência), níveis de espaço, criação e improvisação de movimentos.

Quanto à ordem das habilidades e elementos envolvidos, não houve ênfase em desenvolver primeiro o equilíbrio ou o esquema corporal, mas sim em desenvolvêlos durante todas as sessões e proporcionar o envolvimento dos participantes nos aspectos compreendidos no IAADE.

É importante ressaltar que todo o conteúdo proposto pelo programa de dança educativa respeitou a condição de cada participante, visando estimular e promover o a aprendizagem em dança educativa por meio do processo de aprendizagem sessão a sessão. 


\subsection{ANÁLISE DOS DADOS}

Os dados foram tabelados e analisados de forma quantitativa e qualitativa. Os dados obtidos pelo IAADE receberam tratamento quantitativo, sendo analisados por meio da estatística descritiva. Já os dados obtidos pelo diário de campo foram analisados por meio da análise de conteúdo, tendo como técnica a análise temática (MINAYO, 1999), com a finalidade de relacioná-los aos dados obtidos pelo IAADE.

Para que essa análise fosse realizada, foram relacionadas estruturas semânticas (significantes) com estruturas sociológicas (significados), articulando a superfície dos textos que descreveram e analisaram variáveis psicossociais, contexto cultural e processo de produção da mensagem (MINAYO, 1999).

Foram estabelecidas categorias para atender aos temas encontrados por meio da análise de conteúdo. As categorias foram: a) contato com o próprio corpo; b) contato com o outro; c) o corpo no espaço; d) o corpo em movimento. Todas essas categorias envolveram descrições sobre: a estrutura do programa, suas especificidades e adequações para a população crianças com deficiência física, os cuidados necessários com essa população e a influência da dança observada do início até o final do programa.

Tendo em vista a preocupação com a fidedignidade dos dados obtidos pelo IAADE, foi utilizada a técnica de peer debriefing ou revisão por pares (BRANTLINGER et al., 2005). Sendo assim, $25 \%$ do número total das sessões, determinadas por sorteio, foram observadas por três pesquisadores assistentes (pós-graduandos em Educação Física e/ou em Educação Especial), participantes do Núcleo de Estudos em Atividade Física Adaptada - NEAFA ${ }^{5}$. Esse cuidado foi empregado na pesquisa para equalizar possíveis vieses por parte da pesquisadora que poderiam interferir na determinação dos resultados. Além disso, dois observadores ou mais estão relacionados com o quanto os julgamentos são objetivos e confiáveis, tornando os dados aceitáveis.

\section{RESULTADOS}

A apresentação dos resultados centrou-se em dois aspectos principais: o envolvimento dos participantes com deficiência física ao longo do programa de dança educativa tendo como referência os resultados obtidos pelo IAADE; e aspectos do programa de ensino da dança educativa que exerceram maior ou menor influência na aprendizagem dos participantes, com base no IAADE e no diário de campo.

\subsection{ENVOLVIMENTO DOS PARTICIPANTES COM DEFICIÊNCIA FÍSICAAO LONGO DO PROGRAMA DE DANÇA EDUCATIVA}

O envolvimento individual dos participantes ao longo da intervenção foi baseado na soma da pontuação obtida por meio do IAADE (soma dos escores atribuídos a cada um dos quatro participantes $\mathrm{x}$ itens avaliados $=21$ ) ao longo de cada uma das sessões.

\footnotetext{
5 O NEAFA é o grupo de estudos vinculado ao Departamento de Educação Física e Motricidade Humana da Universidade Federal de São Carlos (DEFMH/UFSCar), cadastrado junto ao Diretório de Grupos de Pesquisa do CNPq.
} 
O valor mínimo a ser considerado é 21 ( $\mathrm{n}$. de questões $=21$ x pontuação mínima $=1$ ) e o máximo é de 105 ( $n$. de questões $=21$ x pontuação máxima $=5$ ).

A Figura 1 apresenta os resultados finais do IAADE obtidos pelos quatro participantes ao longo do programa em cada sessão.

Figura 1 - Envolvimento geral dos participantes.

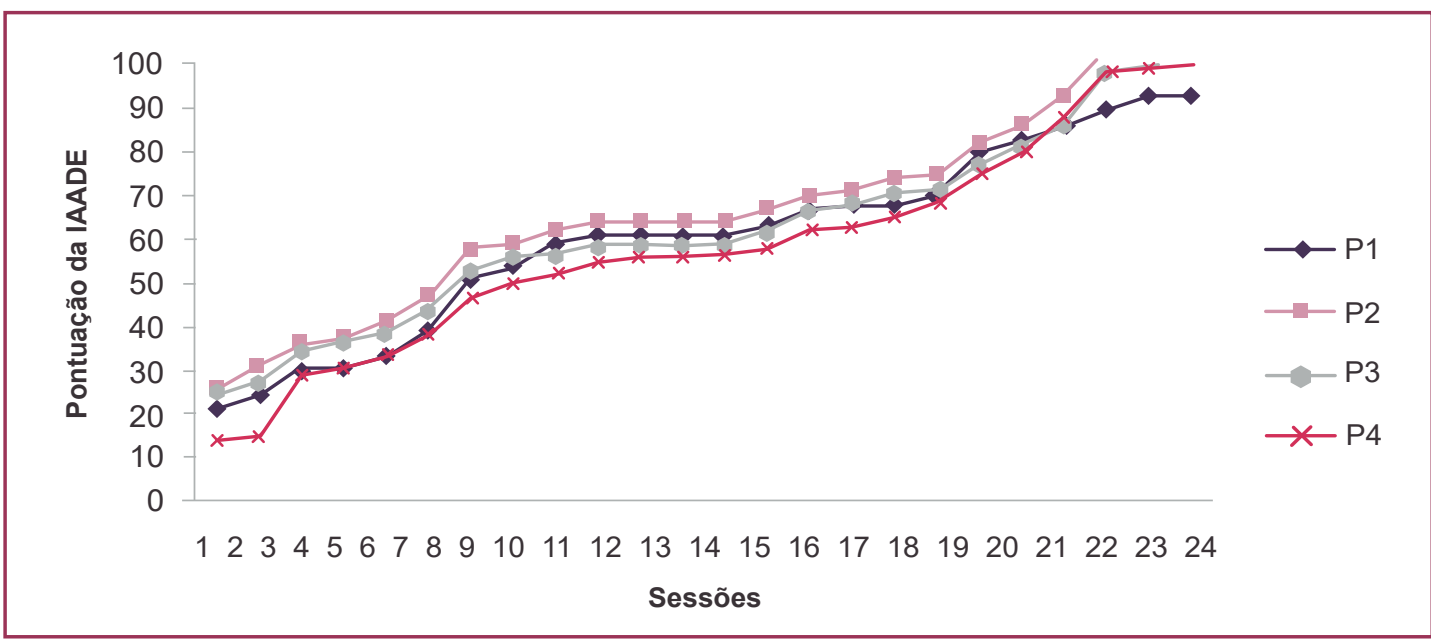

Fonte: elaboração própria

As pontuações iniciais e finais dos participantes, bem como a variação de pontos, podem ser observadas na Tabela 1. Tais números demonstram que P4 foi o participante que obteve maior variação, podendo ser inferido que foi o que teve melhor aproveitamento em comparação aos demais.

Tabela 1 - Pontuação obtida pelos participantes.

\begin{tabular}{cccc}
\hline & Pontuação inicial & Pontuação final & Variação \\
\hline P1 & 21 & 93 & 72 \\
P2 & 26 & 104 & 78 \\
P3 & 26 & 104 & 78 \\
P4 & 14 & 101 & 87 \\
\hline
\end{tabular}

Fonte: elaboração própria.

Ao analisar o valor da pontuação final na última sessão, verifica-se que todos os participantes atingiram pontuações próximas, sugerindo nível semelhante de aprendizagem e também pontuações próximas em relação ao valor máximo alcançado pelo instrumento $(=105)$, permitindo inferir que os participantes obtiveram excelente aproveitamento do programa de dança educativa.

\subsection{ANÁLISE DA INFLUÊNCIA DOS ASPECTOS DO PROGRAMA DE ENSINO EM DANÇA EDUCATIVA}

O programa de ensino em dança educativa foi iniciado pelo aspecto/momento "conhecendo o próprio corpo" (CC), que permaneceu com maior ênfase até a sessão cinco. Durante as sessões seis e sete, foram inseridos conteúdos que desenvolveram 
o "contato com o outro" (CO). Da sessão oito a 19, foram enfatizados os conteúdos acerca do "o corpo no espaço" (CE) e, o "o corpo em movimento" (CM), da sessão 20 a 24.

Para analisar os aspectos do programa de ensino em dança educativa que exerceram maior ou menor influência na aprendizagem das crianças com deficiência física, foi realizada a média da pontuação obtida entre todos os participantes para cada uma das 21 questões componentes do IAADE (Figura 2). Como forma de parâmetro, foram selecionadas a primeira e a última sessão em que cada habilidade e elemento foram desenvolvidos com maior ênfase, para verificar o nível de aprendizagem dos participantes acerca do primeiro contato com tais habilidades e elementos da dança comparando com a última sessão realizada.

Figura 2 - Análise da aprendizagem de cada uma das habilidades e dos elementos constituintes do programa no início e ao término da intervenção.

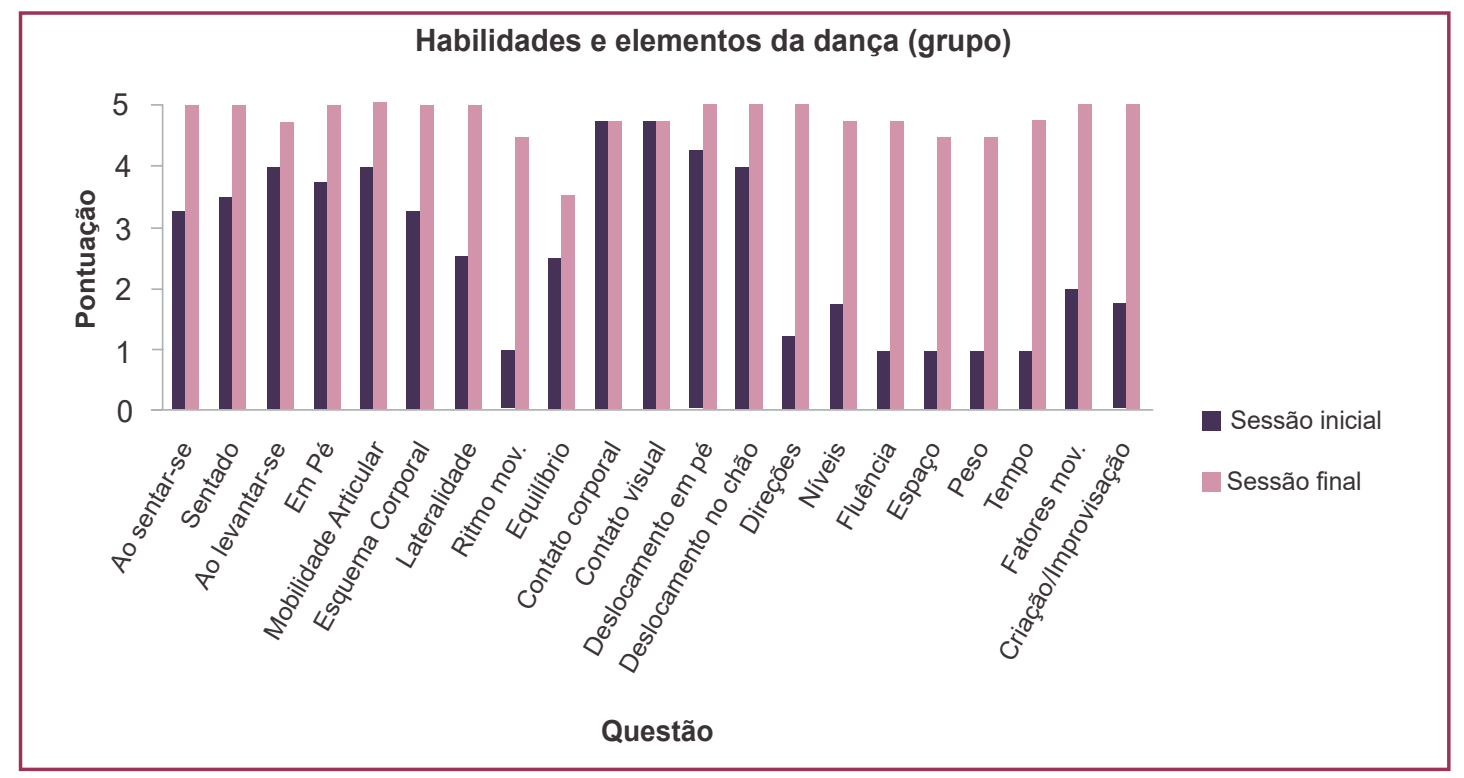

Fonte: elaboração própria.

As questões que demonstraram ganhos expressivos (pontuação um ou dois na primeira sessão e que aumentaram para quatro ou cinco no decorrer do programa) envolveram as seguintes habilidades e elementos: lateralidade; ritmo de movimentos; exploração de direções exploração dos níveis de espaço realização e compreensão dos fatores de movimento "fluência", "espaço", "peso" e "tempo"; a realização dos fatores em conjunto e a improvisação/criação.

Quanto aos fatores de movimento, os participantes demonstraram dificuldades em assimilar as nomenclaturas, mas com relação à movimentação eles demonstraram compreender a diferença entre cada uma das qualidades. O Quadro 3, baseado nos resultados obtidos pelo diário de campo, apresenta os fatores de movimento, as qualidades e os participantes que apresentaram dificuldades. 
Quadro 3 - Aprendizagem dos fatores de movimento.

\begin{tabular}{|c|c|c|c|}
\hline $\begin{array}{l}\text { Fator de } \\
\text { movimento }\end{array}$ & Qualidade & $\begin{array}{l}\text { Dificuldades/ } \\
\text { Participante }\end{array}$ & $\begin{array}{l}\text { Observações do desempenho dos } \\
\text { participantes }\end{array}$ \\
\hline \multirow[t]{2}{*}{ Fluência } & Livre & Não houve. & $\begin{array}{l}\text { - Movimentos contínuos durante as atividades, } \\
\text { rolamentos com fluidez e harmonia, assim } \\
\text { como no alongamento e ao explorar os níveis } \\
\text { de espaço e as direções. } \\
\text { - Ênfase em movimentos grandes e que } \\
\text { exploravam o espaço ao redor. }\end{array}$ \\
\hline & Contida & Não houve. & $\begin{array}{l}\text { - Realização de movimentos próximos ao } \\
\text { corpo. } \\
\text { - Ênfase em movimentos pequenos e simples. }\end{array}$ \\
\hline \multirow[t]{2}{*}{ Espaço } & Direto & Não houve. & $\begin{array}{l}\text { - Facilitou na exploração das direções durante } \\
\text { o deslocamento em pé e no chão. }\end{array}$ \\
\hline & Flexível & Não houve. & $\begin{array}{l}\text { - Influenciou na improvisação de caminhos } \\
\text { diferentes dos movimentos e do deslocamento } \\
\text { pelo chão e em pé. }\end{array}$ \\
\hline \multirow[t]{2}{*}{ Peso } & Leve & Não houve. & $\begin{array}{l}\text { - Movimentos semelhantes ao "caminhar na } \\
\text { Lua", relacionaram com o ritmo mais lento e } \\
\text { com músicas mais calmas. }\end{array}$ \\
\hline & Firme & $\begin{array}{l}\text { Dificuldade na } \\
\text { compreensão do } \\
\text { termo e do movimento } \\
\text { por P1, P2, P3 e P4. }\end{array}$ & $\begin{array}{l}\text { - Compreendiam a diferença entre "leve" e } \\
\text { "firme", mas não compreendiam a realização } \\
\text { desse movimento, que deveria envolver a } \\
\text { força da gravidade com movimentos pesados. }\end{array}$ \\
\hline \multirow[t]{2}{*}{ Tempo } & Súbito & $\begin{array}{l}\text { Dificuldade na } \\
\text { memorização do } \\
\text { termo, mas houve } \\
\text { a compreensão do } \\
\text { movimento por P1 e } \\
\text { P3. }\end{array}$ & $\begin{array}{c}\text { - Realizavam movimentos rápidos. } \\
\text { - P1 e P3 compreendiam a qualidade quando } \\
\text { denominada rápida, e não súbita. O uso do } \\
\text { termo não influenciou no desempenho dos } \\
\text { alunos. }\end{array}$ \\
\hline & Sustentado & $\begin{array}{l}\text { Dificuldade na } \\
\text { memorização do } \\
\text { termo, mas houve } \\
\text { a compreensão do } \\
\text { movimento por P1 e } \\
\text { P3. }\end{array}$ & $\begin{array}{l}\text { - Realizavam movimentos mais vagarosos. } \\
\text { - P1 e P3 compreendiam a qualidade quando } \\
\text { denominada de lento. O uso do termo não } \\
\text { influenciou no desempenho dos alunos. }\end{array}$ \\
\hline
\end{tabular}

Fonte: elaboração própria.

Com relação ao conteúdo do Quadro 4 e a condição individual dos participantes em decorrência da deficiência, não houve diferença significativa na qualidade da movimentação, todos conseguiram movimentar-se dentro das possibilidades pessoais, sendo possível identificá-las, respeitando os limites individuais de cada participante.

Ainda com base no diário de campo, os dados apresentados na Figura 3 demonstram a diminuição nos níveis de apoio (assistência física, demonstração de exercícios e instrução verbal) prestado pela pesquisadora aos participantes ao longo da intervenção. Tal situação sugere o aumento gradual no nível de independência e autonomia dos participantes. Para apresentar os dados dos apoios, foi realizada a média dos participantes por sessão para verificar o desenvolvimento do grupo com relação a estes comandos durante o programa de dança educativa (Figura 3). 
Figura 3 - Média dos tipos de apoio (singular) prestado aos participantes.

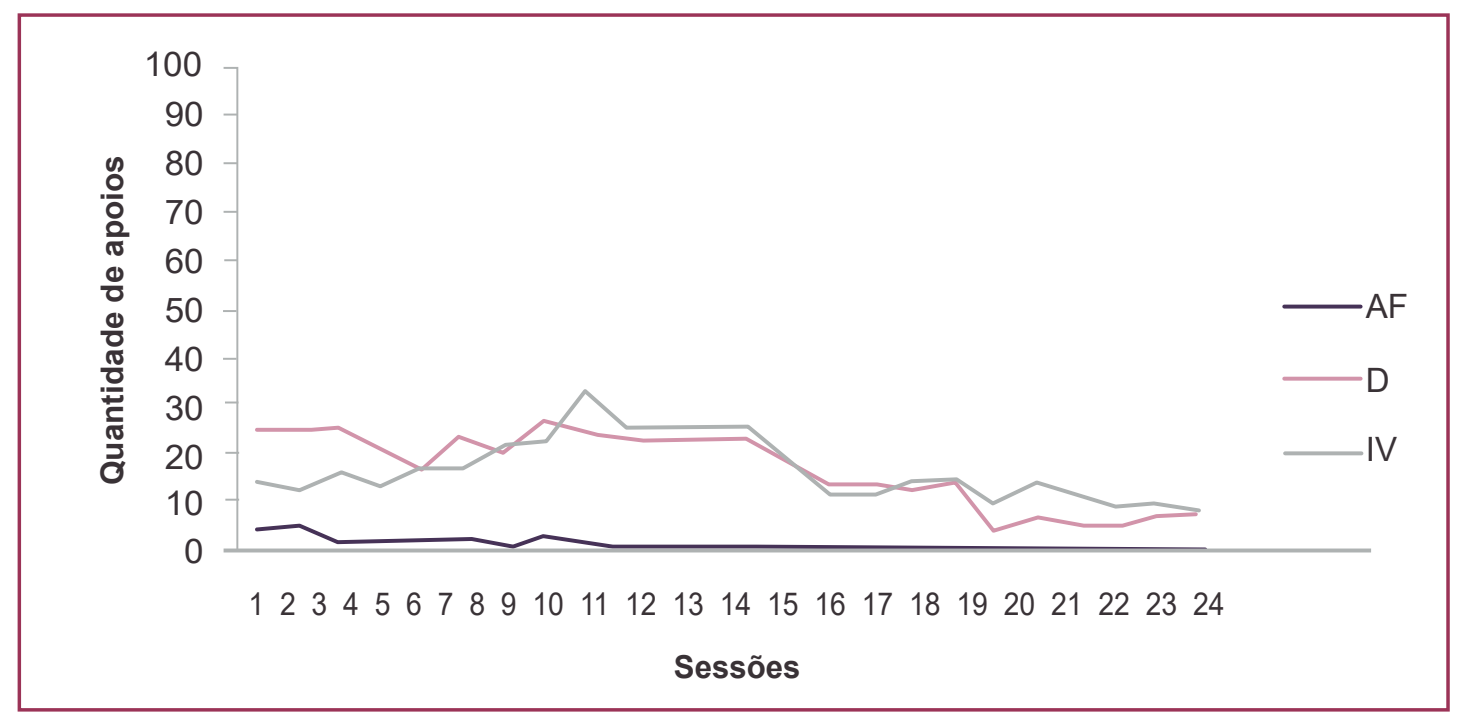

Fonte: elaboração própria.

O diário de campo permitiu ainda identificar quais foram as adaptações recorrentes para que os participantes realizassem as atividades e os ganhos evidenciados durante o programa, conforme explicitado no Quadro 4.

Quadro 4 - Adaptações e repercussões do programa de Dança Educativa.

\begin{tabular}{|c|c|c|}
\hline Participante & Adaptações & Ganhos mais expressivos \\
\hline $\begin{array}{l}\text { P1, P2, } \\
\text { P3 e P4 }\end{array}$ & $\begin{array}{l}\text { - Atividades realizadas em nível } \\
\text { baixo (sentadas); } \\
\text { - Intercalar atividades em pé } \\
\text { (por exemplo, deslocamento) } \\
\text { com atividades sentadas; } \\
\text { - Uso de imagens (por } \\
\text { exemplo, das partes do corpo) } \\
\text { para facilitar a compreensão e } \\
\text { memorização; } \\
\text { - Uso de músicas populares e/ } \\
\text { ou do seu conhecimento para } \\
\text { incentivar a movimentação; } \\
\text { - Uso de objetos para prender } \\
\text { a atenção; } \\
\text { - Atividades em dupla. } \\
\text { - Atividades que envolviam a } \\
\text { movimentação da articulação } \\
\text { (realizar movimentos } \\
\text { semelhantes). }\end{array}$ & $\begin{array}{l}\text { - Aumento do repertório de movimento; } \\
\text { - Reconhecimento das partes do corpo; } \\
\text {-Reconhecimento dos lados direito e esquerdo em } \\
\text { si e no outro; } \\
\text { - Melhoria no deslocamento do chão (rolamentos } \\
\text { contínuos e fluidos); } \\
\text {-Melhoria no deslocamento em pé (agilidade ao } \\
\text { caminhar e ao explorar as direções); } \\
\text { - Melhoria na transição da posição em pé para } \\
\text { sentado e deitado (e vice-versa) (agilidade ao } \\
\text { explorar os níveis baixo, médio e alto); } \\
\text { - Criação de movimentos diferenciados; } \\
\text { - Improvisação. } \\
\text { - Segurança ao realizar os movimentos solicitados } \\
\text { e ao criar/improvisar; } \\
\text { - Compreensão e realização dos fatores de } \\
\text { movimento; } \\
\text { - Relações interpessoais; } \\
\text { - Comunicação; } \\
\text { - Interação; } \\
\text { - Relações interpessoais. }\end{array}$ \\
\hline
\end{tabular}

Fonte: elaboração própria.

Em suma, os participantes demonstraram um envolvimento expressivo em relação a todos os aspectos avaliados no programa de Dança Educativa. Além de melhorarem lateralidade, ritmo de movimentos, exploração de direções, exploração dos níveis de espaço, realização e compreensão dos fatores de movimento "fluência", "espaço", "peso" e "tempo", a realização dos fatores em conjunto e a improvisação/ 
criação, os participantes conseguiram realizar movimentos coreográficos, ou seja, movimentos implementados pelo corpo, que podem ser descritos como "dançar". Tal apontamento reforça que o programa em questão foi eficiente para desenvolver a aprendizagem em dança educativa de crianças com deficiência física preponderando uma avaliação somativa, enfatizada no processo de ensino e aprendizagem.

\section{DISCUSSÃO}

Todos os participantes demonstraram envolvimento no período de intervenção quando as habilidades e elementos da dança foram inseridos, corroborando a eficiência do programa estruturado e organizado, centrado no processo de ensino e aprendizagem.

Para que esse resultado fosse atingido, foi necessário o estabelecimento de relações entre conteúdos, objetivos e nível de desempenho dos participantes organizados em uma sequência lógica para que as tarefas fossem realizadas tanto no que envolve a organização do programa como um todo, quanto o planejamento aula a aula.

Ao planejar cada aula foram consideradas as dificuldades e possibilidades dos participantes, as adequações necessárias e a verificação dos conceitos e/ou habilidades compreendidos por eles, proporcionando a igualdade de oportunidades a fim de que acontecesse o processo de ensino (SOUZA, 1994).

Além do mais, a própria dança educativa destaca o processo e não o produto, pois não prepondera a perfeição, criação ou execução de movimentos sensacionais, sendo seu ensinamento baseado na compreensão e na prática do movimento, com ênfase no ensino do todo e não das partes (LABAN, 1990; MARQUES, 2011).

A ênfase no processo também demonstra a preocupação em envolver a ação do professor no sentido de despertar e orientar o aluno para o movimento livre, preponderando uma ação consciente, reflexiva e que respeita a individualidade de cada aluno (BERNABÉ, 2001).

As habilidades e elementos do programa de dança educativa com maior incremento acompanham os resultados apresentados pelos seguintes estudos que envolveram dança e crianças com deficiência física: Silva, Carvalho e Millen Neto (2009), Santos e Braga (2010) e Maia (2012). Esses autores demonstraram benefícios envolvendo aspectos motores, como lateralidade e ritmo, além da organização espacial e temporal.

Os participantes conseguiram compreender as diferentes formas de movimentos e as diferentes qualidades existentes entre eles, mesmo que não conseguissem assimilar os termos relativos aos movimentos. A dança educativa não busca a padronização, mas a expressão individual com base na consciência da movimentação e no desenvolvimento da compreensão e da criação (LABAN, 1990; MARQUES, 2011).

Houve questões em que os participantes, nesse caso os que tinham paralisia cerebral, demonstraram pequeno avanço, sendo justificado pelas limitações motoras 
associadas à característica da diparesia espástica, como, por exemplo, o equilíbrio em um único apoio e o deslocamento em pé.

Todavia, os fatores de movimento devem ser desenvolvidos visando a possíveis benefícios motores envolvendo tônus muscular e a experimentação e vivência de diversas situações, para que possam conhecer seu próprio corpo e reconhecer suas possibilidades para enfatizar na funcionalidade.

Com relação ao contato visual e corporal, todos os participantes apresentaram ótima pontuação já na primeira sessão em que foi desenvolvida, mantendose alta durante o programa. Isso sugere a ótima relação entre os participantes e entre participantes e a professora/pesquisadora, demonstrando a capacidade de comunicação e interação.

Embora o IAADE não demonstre envolvimento acerca do contato visual e corporal, os registros realizados no diário de campo indicaram que as relações interpessoais foram intensificadas ao longo do programa, como atitudes de amizade e companheirismo tanto com a professora quanto entre os participantes.

Esse dado relaciona-se com aqueles apresentados por Maia (2012), que verificou melhorias acerca dos aspectos cognitivos e interativos dos participantes com deficiência física em um programa de dança terapêutica. $E$ também os estudos de Santos e Braga (2010), que apontaram melhorias do comportamento, da autoestima e da saúde mental das crianças com paralisia cerebral que frequentaram as aulas de dança.

O diário de campo aponta, também, que houve melhorias envolvendo o interesse em descobrir movimentos diferentes durante as atividades propostas e em criar sequências coreográficas.

Assim, como Laban (1990) e Marques (2002) afirmam, a aprendizagem da dança educativa deve conceder ao participante a capacidade e a agilidade necessárias para realizar movimentos com autonomia, criatividade e segurança, a partir de qualquer impulso voluntário ou involuntário, enfatizando a descoberta pessoal e o desenvolvimento da personalidade de cada um, independentemente de sua condição física.

Estudos como os de Silva, Carvalho e Millen Neto (2009) corroboram o fato de a dança influenciar positivamente a autonomia de crianças com deficiência física, o que, consequentemente, interfere positivamente na autoestima, tendo em vista a realização de movimentos diferentes e mais funcionais do que os que realizavam antes do programa de dança.

Assim também, Ferreira (2000) e Ferreira e Ferreira (2004) reforçam que a dança contribui significativa e positivamente nas pessoas com deficiência física, proporcionando diferentes possibilidades de movimentos que ampliam o conhecimento e a descoberta de habilidades motoras que podem auxiliar no cotidiano, desenvolvendo o autoconhecimento e explorando várias formas de expressão e de comunicação. 


\section{CONCLUSÕES}

O instrumento empregado (IAADE) demonstrou ser aplicável à amostra (crianças com deficiência física) e ao escopo do presente estudo, visto que foi centrado no processo de ensino da dança educativa especificamente orientado à população em questão.

O IAADE constatou melhorias expressivas abarcando: lateralidade; ritmo de movimentos; exploração de direções; exploração dos níveis de espaço; realização e compreensão dos fatores de movimento "fluência", "espaço", "peso" e "tempo"; a realização dos fatores em conjunto; e a improvisação/criação. O diário de campo demonstrou que os participantes obtiveram resultados positivos acerca dos aspectos motores, sociais e emocionais, pois aprimoraram as habilidades destacadas pelo IAADE e intensificaram as relações sociais (atitudes de amizade, companheirismo e respeito).

Foi observado que os apoios diminuíram ao longo da intervenção, provavelmente devido à melhoria na autonomia e segurança adquirida pelos alunos, à fluidez e qualidade dos movimentos e à compreensão das atividades realizadas.

Considera-se que o programa de dança educativa para crianças com deficiência física nas condições vivenciadas durante sua aplicação neste estudo demonstrou efetividade, tendo em vista o envolvimento satisfatório dos participantes acerca da avaliação realizada pelo IAADE e pelo diário de campo.

Foram identificadas as seguintes limitações no estudo: necessidade de ampliar o período de intervenção, sobretudo para o desenvolvimento do momento quatro ("corpo em movimento"), pelo fato de ser o momento que envolveu todo o conteúdo ministrado, a fim de assegurar a assimilação da proposta; importância de envolver uma amostra maior e mais representativa, a fim de aumentar a possibilidade de replicação do estudo; sugere-se ainda que o programa de dança, de forma geral, envolva mais incentivo à improvisação de movimentos; disponibilidade maior para o desenvolvimento/elaboração de coreografias; apresentação de coreografias para familiares, parentes e amigos; utilização de vídeos com bailarinos e/ou grupos de pessoas com deficiências, para demonstrar as suas possibilidades e potencialidades durante as apresentações artísticas; convite de outros profissionais das áreas da arte, da educação, da reabilitação e do esporte para apresentar as diferentes vertentes da dança, informando que há outras possibilidades, mas que a ênfase de suas sessões envolveu a finalidade pedagógica; e validação do instrumento IAADE.

Como sugestão para futuros estudos, recomenda-se que as intervenções em Dança Educativa possam abranger população mais diversificada, verificando a aplicabilidade do programa e do instrumento a diferentes condições de deficiência e vários níveis de envolvimento. Recomenda-se ainda que o Instrumento de Acompanhamento da Aprendizagem em Dança Educativa (IAADE) seja submetido ao processo de validação de conteúdo, de forma a aumentar a sua confiabilidade e fidedignidade. 


\section{REFERÊNCIAS}

BERNABÉ, Rosangela. Dança e deficiência: proposta de ensino. 2001. 97f. Dissertação (Mestrado em Educação Física) - Faculdade de Educação Física, Universidade Estadual de Campinas, UNICAMP, 2001.

BRANTLINGER, Ellen; JIMENEZ, Robert; KLINGNER, Janette; PUGACH, Marleen; RICHARDSON, Virginia. Qualitative studies in Special Education. Council for Exceptional Children, v.71, n. 2, p. 195-207, 2005.

FERREIRA, Eliana Lucia. O sentido do sentir: corpos dançantes em cadeiras de rodas. Revista Conexões, v. 0, n. 4, p. 89-98, 2000.

FERREIRA, Eliana Lúcia; FERREIRA, Maria Beatriz R. A possibilidade do movimento corporal na dança em cadeira de rodas. Revista Brasileira de Ciência e Movimento, v. 12, n. 4, p. 13-17, 2004.

FREIRE, Irene M. Dança-educação: o corpo e o movimento no espaço do conhecimento. Cadernos Cedes, v. 21, n. 53, p. 31-55, 2001.

GUERZONI, Vanessa P. D.; BARBOSA, Adriana P.; BORGES, Ana Cristina C.; CHAGAS, Paula C. C.; GONTIJO, Ana Paula B.; ETEROVICK, Fernanda; MANCINI, Marisa C. Análise das intervenções de terapia ocupacional no desempenho das atividades de vida diária em crianças com paralisia cerebral: uma revisão sistemática da literatura. Revista Brasileira de Saúde Materna e Infantil, v. 8, n. 1, p. 17-25, 2008.

LABAN, Rudolf. Dança educativa moderna. São Paulo: Ícone, 1990.

LOPES, Keyla F. Identidade social e autoconceito do dançarino em cadeira de rodas. 2011. 132f. Dissertação (Mestrado em Educação Física) - Faculdade de Educação Física, Universidade Estadual de Campinas, Campinas, 2011.

MACHADO, Lavinia T. A. A dançaterapia melhora a qualidade de vida e a função neuromuscular de indivíduos com transtornos neuromotores. 2010. 137f. Dissertação (Mestrado em Ciências da Saúde) - Núcleo de Pós-graduação em Medicina, Universidade Federal de Sergipe, Aracaju, 2010.

MAIA, Elba T. A dança como instrumento de intervenção neuropsicológica em crianças com encefalopatia crônica não progressiva: um estudo etológico não controlado. 2012. 74f. Dissertação (Mestrado em Ciência do Comportamento) - Departamento de Processos Psicológicos Básicos, Universidade de Brasília, Brasília, 2012.

MARCONI, Marina A; LAKATOS, Eva M. Técnicas de pesquisa: planejamento e execução de pesquisas, amostragens e técnicas de pesquisa, elaboração, análise e interpretação de dados. 2 ed. São Paulo: Atlas, 2008.

MARQUES, Isabel A. Revisitando a dança educativa moderna de Rudolf Laban. Revista Sala Preta, v. 2, n. 1, p. 276-281, 2002.

MARQUES, Isabel. Ensino da dança hoje: textos e contextos. 6. ed. São Paulo: Cortez, 2011.

MAUERBERG-DECASTRO, Eliane. Atividade física adaptada. Ribeirão Preto: Tecmedd, 2005.

MINAYO, Maria Cecilia S. O desafio do conhecimento: pesquisa qualitativa em saúde. 6. ed. São Paulo: Hucitec, 1999. 
PAULA, Otávio R. Intensidade de esforço na competição de dança esportiva em cadeira de rodas. 2010. 56f. Dissertação (Mestrado em Educação Física) - Faculdade de Educação Física e Desportos, Universidade Federal de Juiz de Fora, Juiz de Fora, 2010.

ROSSI, Patricia. Programação de ensino em dança educativa voltada a crianças com deficiência física. 2014. 170f. Dissertação (Mestrado em Educação Especial) - Programa de Pós-graduação em Educação Especial, Universidade Federal de São Carlos, São Carlos, 2014.

ROSSI, Patricia; MUNSTER, Mey A. V. Dança e deficiência: uma revisão bibliográfica em teses e dissertações nacionais. Movimento, v.19, n. 4, p. 181-205, 2013.

SAMPIERI, Roberto H.; COLLADO, Carlos H.; LUCIO, Maria P. B. Metodologia de pesquisa. São Paulo: McGraw-Hill, 2006.

SANTOS, Luciana B.; BRAGA, Douglas M. Dança e fisioterapia para crianças e adolescentes com paralisia cerebral. Revista Neurociência, v. 18, n. 4, p. 437-442, 2010.

SANTOS, Renata F.; GUTIERREZ, Gustavo L.; ROBLE, Odilon D. Dança para pessoas com deficiência: um possível elemento de transformação pessoal e social. Revista Brasileira de Ciência do Esporte, v. 41, n. 3, p. 271-276, 2019.

SILVA, Fernanda; CARVALHO, Bruna A.; MILLEN NETO, Álvaro R. Dança em cadeira de rodas e paralisia cerebral: estudo de caso da menina Laura. Revista Conexões, v. 7, n. 1, p. 121-134, 2009.

SOUZA, Clariza P. Avaliação Escolar: limites e possibilidades. In: Série Ideias, n.22. São Paulo: FDE, 1994. p.89-90. 
Abstract: This study aimed to analyze the involvement of participants with physical disabilities in certain elements of an educational dance program and to verify which aspects of the intervention had greater or lesser influence. This is a field research study characterized as a program evaluation study, based on intervention in educational dance in 24 sessions. Four children with physical disabilities participated in this research. The data collection instruments were a field diary and the Follow-up Instrument of Learning in Educational Dance (FILED). Data analysis was performed qualitatively and quantitatively, based on descriptive statistics. The dance skills and elements that indicated expressive results were laterality, movement rhythm, exploring directions (front, side and back) and space levels (low, medium and high), understanding and performance of movement factors "fluency," "weight," "time" and "space."

Keywords: Dancing. Child. Disabled persons. Special Education.

Resumen: Este estudio tuvo como objetivos analizar la participación de niños con discapacidad física en determinados elementos (rodar y moverse por el espacio, incluyendo los niveles, las direcciones y los factores de movimiento) de un programa de danza educativa y verificar en cuáles aspectos analizados por la escala de evaluación en danza educativa la intervención promovió mayor o menor influencia. Se trata de una investigación de campo del tipo estudio de evaluación de programa. Participaron cuatro niños con discapacidad física. Los instrumentos para la recolección de datos fueron: diario de campo e Instrumento de Acompañamiento del Aprendizaje en Danza Educativa (IAADE). El análisis de los datos se realizó de forma cualitativa y cuantitativa (estadística descriptiva). Se observó que las habilidades y los elementos que indicaban mejoras expresivas fueron: lateralidad, ritmo de movimientos, exploración de direcciones (frontal, lateral y posterior) y niveles de espacio (bajo, medio y alto), comprensión y realización de los factores de movimiento "fluidez", "peso", "tiempo" y "espacio".

Palabras clave: Baile. Niño. Personas con discapacidad. Educación especial. 


\section{LICENÇA DE USO}

Este é um artigo publicado em acesso aberto (Open Access) sob a licença Creative Commons Atribuição 4.0 Internacional (CC BY 4.0), que permite uso, distribuição e reprodução em qualquer meio, desde que o trabalho original seja corretamente citado. Mais informações em: http://creativecommons.org/licenses/by/4.0

\section{CONFLITO DE INTERESSES}

Os autores declararam que não existe nenhum conflito de interesses neste trabalho.

\section{CONTRIBUIÇÕES AUTORAIS}

Patricia Rossi-Andrion: Responsável pelo desenvolvimento da pesquisa, bem como coleta e análise de dados, escrita do artigo.

Mey de Abreu van Munster: Orientou o processo de desenvolvimento da pesquisa, desde a redação, até coleta e análise dos dados.

\section{FINANCIAMENTO}

O presente trabalho foi realizado com apoio da Coordenação de Aperfeiçoamento de Pessoal de Nível Superior - Brasil (CAPES) - Código de Financiamento 001. This study was financed in part by the Coordenação de Aperfeiçoamento de Pessoal de Nível Superior - Brasil (CAPES) - Finance Code 001.

\section{ÉTICA DE PESQUISA}

O projeto em questão foi submetido ao Comitê de Ética e Pesquisa em Seres Humanos da Universidade Federal de São Carlos - CEP/UFSCar e aprovado pelo parecer n. 72041.

\section{COMO REFERENCIAR}

ROSSI-ANDRION, Patricia; MUNSTER, Mey de Abreu van. Dança educativa para crianças com deficiência física: repercussões de um programa de ensino. Movimento (Porto Alegre), v.27, p. e27020, jan./dez. 2021. Disponível em: https:// seer.ufrgs.br/Movimento/article/view/102748. Acesso em: [dia] [mês abreviado]. [ano]. DOI: https://doi.org/10.22456/1982-8918.102748

\section{RESPONSABILIDADE EDITORIAL}

Alex Branco Fraga*, Elisandro Schultz Wittizorecki*, Ivone Job*, Mauro Myskiw*, Raquel da Silveira*

*Universidade Federal do Rio Grande do Sul, Escola de Educação Física, Fisioterapia e Dança, Porto Alegre, RS, Brasil. 